\title{
ADVENTURE THERAPY: USING ADVENTUROUS ACTIVITIES AS OCCUPATIONAL THERAPY
}

\author{
Helen Jeffery
}

\section{INTRODUCTION}

Adventure therapy commonly utilises adventure-based activities, experiential learning theory and outdoor environments to facilitate a therapeutic effect. Adventure therapy is an emerging intervention utilised by mental health clinicians, often within services for youth. This qualitative descriptive study explored the practice and use of theory with seven New Zealand occupational therapists who use adventure therapy, to ascertain the fit (or otherwise) between adventure therapy and occupational therapy. There are practice and philosophical elements of adventure therapy that are compatible with occupational therapy, including therapeutic use of activity. Differences include adventure therapy's purposeful use of novel activities and environments, and prescription of activities which is in contrast with occupational therapy's usual focus on familiar everyday environments and clientselected activities. This paper presents findings which explore of the value of activity as therapy, compared with talk as therapy. Whilst adventure therapy does not provide the therapist with scope to fulfil all the elements of usual occupational therapy with the client, it can be used as an approach to occupational therapy practice. The use of adventure-based activities, whilst not usual activities for occupational therapy practice, is attractive to youth. It is argued that adventure therapy is a powerful example of the use of activity as a means to an occupational end. Occupational therapists are well positioned to use adventure therapy as a component of their overall occupational therapy practice.

\section{BACKGROUND}

There is no one definition of what adventure therapy is or of who an adventure therapist is. The way the field is described is often related to the client population, the service model, and the background of the facilitator (Alvarez \& Stauffer, 200I; Itin, 1998; Mossman, 2005). Settings that use adventurous activities with groups include both health and education, and it is here that theories and practices between health and education merge. Adventure therapy activities are typically situated in the outdoors and might include any number of activities such as bush walking, kayaking, climbing, high ropes courses and initiative or problem-solving games. The field can be viewed as a continuum, from mainstream schools with an emphasis on youth development (outdoor and environmental education) through to specialist mental health services (Jeffery, 2017). The model of service provision may include an hour-long session through to a multi-day journey. Generally, adventurous activities are used following experiential learning theory, and are facilitated with youth and in groups. Planned outcomes are not related to developing skills in the activity itself (so not to learn to kayak) but rather personal growth, development of intra-personal and inter-personal skills, increase in self-esteem, resilience and confidence, and a stronger sense of self-identity (Newes \& Bandoroff, 2004).

The use of adventurous activities and/or the outdoor environment are used by clinicians (working alongside outdoor specialists where appropriate) as a part of overall therapy. The definition provided by Gass, Gillis, and 
Russell (20I2) summarises an understanding of adventure therapy in line with many practices in New Zealand: "Adventure therapy is the prescriptive use of adventure experiences provided by mental health professionals, often conducted in natural settings that kinesthetically engage clients on cognitive, affective, and behavioral levels" (p. I). The health professions who most influenced the development of the field came from psychotherapy, social work and counselling backgrounds, resulting in an emphasis on the integration of talk-based therapies alongside the engagement with activities. Crisp (1996) identified that some occupational therapists were using adventure therapy, and that because of their training in and emphasis on the therapeutic use of activity, occupational therapy is an ideal profession to work in this field. However, the use of adventure therapy by occupational therapists is not evident in occupational therapy literature. This research therefore sought to explore occupational therapists' use of adventure therapy from theoretical, philosophical and practice perspectives, and to ascertain the fit (or otherwise) between the two fields.

\section{METHOD}

As current understanding of occupational therapists' use of adventure therapy is not evident in the literature, qualitative descriptive methodology was chosen. This provides a way of capturing the facts as they are in order to offer a comprehensive summary of practice (Sandelowski, 2000). Recruitment of research participants was through adventure therapy and occupational therapy networks in New Zealand. Eight potential participants volunteered, with seven ultimately interviewed. Participant inclusion criteria for the study was New Zealand occupational therapists who are working (or have worked within the past 10 years) and using adventure therapy in New Zealand. Ethics approval was granted by the Otago Polytechnic Ethics Committee in October 2013.

Semi-structured interviews were conducted, in line with recommended practice for qualitative descriptive methodology (Neergaard, 2009). Questions focused on ascertaining existing knowledge and experiences of participants. Interview transcriptions were thematically analysed following Field and Morse (1996) four cognitive stages: comprehending (understanding what is in the data), synthesizing or decontextualizing (understanding the norms and averages of the data), theorising (linking data to established theory and organizing data to show what is significant), and re-contextualising (linking new findings to the literature). Pilot interviews were conducted to check the effectiveness of the interview guide, modifications were made in response to feedback. Interviews were recorded and transcribed, transcripts were returned to participants for member checking. Reflexivity was addressed by critical reading of transcripts, and through thematic checking by academic colleagues in outdoor education and in occupational therapy. Gender-neutral pseudonyms were allocated and transcripts were edited to avoid identification of participants.

\section{RESULTS}

The theme presented here is the use of activity as therapy, which emerged as both familiar to participants (occupational therapists use activity therapeutically), and unfamiliar to participants (adventure therapy uses activity in a different way from usual occupational therapy practice). Participants identified that they use adventure therapy as a means to achieving an occupational outcome, and that their therapeutic use of talk differs from adventure therapy practitioners who come from counselling, psychotherapy and other talk-based therapy professions.

\section{Activity as therapy}

"They are both activity focused at the core of them I think." (participant Dale)

Occupational therapists utilise occupation (or activity) as a therapeutic medium, and participants identified that adventure therapy also does this. The adventurous activities were considered as therapy, with participants understanding and endorsing the therapeutic benefits of simply engaging in the activity. Occupational therapy 
and adventure therapy share a philosophical assumption that the activities individuals engage in are a determinant of health, and that engagement in activities can influence health. However, adventure therapy's use of activity as a therapeutic intervention is different from occupational therapy's broader holistic view of the individual as an occupational being. Participants' observations and the literature reviewed describe adventure therapy using prescribed unfamiliar activities in novel environments, often to provide challenge with an element of perceived risk. The intent is to allow the client to develop insight into their usual, possibly unhelpful, responses to challenge and try new ways of responding. Occupational therapy in contrast generally focuses on the client's everyday activities in familiar environments, has a more pragmatic approach and works on real life problems. In occupational therapy intervention, engagement in the activity may be viewed as therapy in itself, whereas in adventure therapy debriefing (facilitated reflection) the activity is considered an important component of the process.

\section{Prescribed activity}

"OT looks more at the real-life picture and is looking at developing skills for occupations more specifically whereas adventure therapy is 'OK we have done something now what have we learned from that?" (participant Chris)

As the activities are prescribed, there is potential for clients to never do the activities again in the future, and for them to not find them meaningful or satisfying when engaged in them - this is at odds with occupational therapists' usual use of activity. However, participants understood the value of adventure therapy activities having the added dimension of often being novel for the client, with an element of challenge. This was particularly beneficial for youth who are attracted to the adventurous nature of the activities and often find this approach to therapy more accessible than talk-based therapy in an interview room. Extensive debriefing of clients' engagement in and behaviour during activities is a feature of adventure therapy that is considered important for learning. Although participants appreciated this, they considered this different from occupational therapy and recognised benefits from the activity irrespective of the debriefing phase.

\section{Activity that is novel}

"...so we don't just do an activity, it's about the activity

as the vehicle for change." (participant Chris)

Participants identified that therapeutic use of activity is important in adventure therapy and in occupational therapy. However, adventure therapy more often uses unfamiliar and one-off experiences, whereas occupational therapy has a focus on the every-day activities that people need or want to do in their usual lives. Although a significant difference, participants saw the benefits in using these experiences as a vehicle for change. The value of being in a novel social environment was acknowledged as Jessie articulated:

"... allows a chance for reflection, away from the usual lives...creating the challenge that was in a different setting so not their usual challenges that they faced when they were at home..."

The every-day nature of activities usually used by occupational therapists was linked to clients selecting aspects of their every-day life that needed changing, and to therapists' use of skill development and education to facilitate enhanced engagement in essential activities and participation in home communities.

\section{Talk-based therapy in adventure therapy}

"...when we are doing something with someone we get richer info than asking someone questions in a sterile room..." (participant Morgan) 
Participants also spoke of the way engagement with activities, often shared with the therapist, creates an environment that is conducive to self-disclosure and sharing. Simply engaging in an activity alongside the therapist can assist the person to feel more comfortable engaging in conversation. This was viewed as a usual benefit of engaging in activities with a therapist, but some considered engagement in challenging activities and sharing the living environment on multi-day trips enhanced this potential for connection and relationship development.

However, the extent to which talk-based therapies were used within adventure therapy (particularly in the debriefing stage) was identified as different from usual occupational therapy. Participants described feeling underequipped in terms of using talk as therapy and expressed belief in the value of sometimes letting the engagement in activity speak for itself.

"Sometimes I think yes that's great we have someone engaged, that's good, they're doing alright or well, and I think sometimes I might see the value in that whereas another clinician whose not an OT might say well we're only half way there, we've got to debrief this in a really meaningful way." (participant Morgan)

\section{Transferring the learning}

"... real kind of the guts of the occupational therapy is the merging...

is the transference of those lessons from the adventure and the outcomes into the everyday life." (participant Dale).

Participants spoke of the importance of helping the client transfer associated learning back to their home environment and lifestyle. They understood that adventure therapy can help people develop skills to engage in expected roles in their usual environment as participant Chris described:

... to do things to improve their function and improve their ability to manage their lives and to kind of do the normal occupational roles of being a school member, a family member, a friend all or those sorts of things are the legitimate kind of roles for people at this age group... I think adventure therapy aids improvement in those roles... (participant Chris)

Most participants spoke of the importance of helping the client transfer associated learning back to their home environment and lifestyle. Although both fields have a focus on transferring the learning back to the every-day environment, participants spoke of occupational therapy doing this much more pragmatically than adventure therapy, given that occupational therapists usually focus on the lived environment. Almost all participants incorporated the adventure therapy component of their work into overall broader mental health occupational therapy intervention.

\section{DISCUSSION}

The World Federation of Occupational Therapists (2018) defines occupational therapy as:

... a client-centred health profession concerned with promoting health and well-being through occupation. The primary goal of occupational therapy is to enable people to participate in the activities of everyday life. (p. 4)

The occupational therapy profession clearly uses occupation (activity) both as therapy and as the outcome of therapy. Trombly (1995) helpfully describes these two aspects of occupational therapy's use of activity as occupation as end - the occupations people need to engage with in their lives, and occupation as means - the use of activities to help individuals maintain or enhance health and reach occupation goals. Gray (1998) encourages 
occupational therapists to work from both ends in unison. The data show that participants were working from both perspectives. Their use of adventure therapy is occupation as means where challenging activities, often contrived and a one-off experience, facilitate learning skills and developing insights that will support changes in occupational identity and engagement. Their overall therapy focus may remain as occupation as ends where the real-life occupational roles and performance of the individual are the focus. The way that they framed activities for their clients and their emphasis on finding meaning and purpose wherever possible (despite the actual activities being novel and prescribed) enhanced their ability to use adventure activities as a means to change in overall occupational terms.

Adventure therapy has a prescriptive approach to activity, where experiences are intentionally created to meet clients' needs (Ames, 2014). Occupational therapists who are working from the contemporary paradigm (Kielhofner, 2009) may feel uncomfortable with prescribing activity in this structured way, although there are other practice areas in mental health occupational therapy where activities may be prescribed, for example art activities in an inpatient setting. Participants seemed able to support the adventure therapy process because they believed in the potential benefit of it for their clients. However, participants qualified their use of activity in adventure therapy by incorporating occupational therapy concepts, for example by selecting activities in terms of meaningfulness for the clients, or incorporating autonomy and choice which is consistent with occupational therapy's client-centred approach (Boniface \& Seymour, 2012; Creek, 2014). This insistence on incorporating meaningfulness or client choice is one significant way in which the practice of some adventure therapy and occupational therapy's use of adventure may be different.

Occupational therapy's body of knowledge draws from other professions and occupational therapists are used to integrating theory from other disciplines (Creek, 2014; Kielhofner, 2009). Mental health occupational therapists tend to use approaches from psychology, particularly from positive psychology theory, such as positive cognitive behavioural therapy (Bannink, 2013), solution focused therapy (Hawkes, Marsh, \& Wilgosh, 1998), mindfulness (Langer, 1989), and motivational interviewing (Miller, 2013). These approaches are client centred, have strengths focus, and seek solutions and positive change rather than being deficit focused. They are compatible with strengthsbased and recovery philosophies advocated in mental health service provision in New Zealand.

These positive psychology approaches are starting to feature in adventure therapy literature (Berman \& DavisBerman, 2005; Wasserburger, 2012) and participants identified they were familiar with them. However, participants felt hindered in their application of some psychology-based therapies due to limited training and the emphasis on talk in them. The psychology approaches often use talk as therapy, where the spoken interaction itself is the therapy and there is considerable emphasis placed on what to say and how to say it. This contrasts with talk within therapy, where the interaction is for safe and effective facilitation of the activity. Despite the activity-based nature of adventure therapy, there has been considerable influence in its development and research by talk-based therapists such as counsellors and psychotherapists. This has likely influenced the emphasis on the use of talk as therapy within adventure therapy, where many consider the most powerful element of adventure therapy is in the debriefing stage following the activity, or the psychotherapy following the experience. As occupational therapy has such an occupation focus, both as a means and purpose of therapy, occupational therapists are less likely to use talking therapies as their primary intervention. Occupational therapists' use of adventure therapy may be an example of using the benefits of the psychology-based theories integral to adventure therapy through skilled facilitation of the activity, and through the use of activities rather than talk in the debriefing phase.

Planned outcomes from adventure therapy are in relation to the individual despite it being conducted in groups. A challenge for adventure therapy is to ensure individual needs are met and learning is transferred to the home environment. Kimball and Bacon (1993) identify that transferring learning from the experience to real life is difficult, partly due to the extreme difference between the environment of therapy and the individual's usual environment. Gass et al. (2012) proposes numerous methods to enhance transferring, however most are reliant on the individual being able to use goal setting, make metaphorical links, and the therapist knowing the individual well. Provided 
occupational therapists are using the adventure therapy process as a part of usual occupational therapy, they are likely to have a good understanding of the individual's home environment and of the practical issues in their life. This enhances their capacity to facilitate transfer of learning from the adventure experience to home. Additionally, occupational therapists naturally select and utilise elements of the adventure experience to develop useful practical skills such as meal preparation on a camping trip. These are strengths in terms of facilitating the transfer of useful learning effectively.

\section{CONCLUSION}

This research found that there is fit between adventure therapy and occupational therapy. In common are the therapeutic use of activity and environment (physical and social), utilizing using the benefits of shared experiences with and between clients, groupwork and intentional facilitation of experiences that enhance coping and function in everyday life. Differences in the way that activity is used between adventure therapy and occupational therapy exist. Adventure therapy's intentional use of novel activities contrasts with occupational therapy's usual focus on everyday activities that the client needs or wants to do. In addition, adventure therapy practitioners more commonly use talk as therapy during and/or after the activity experience as an integral part of the therapy. This is to an extent that is not usual occupational therapy practice. Occupational therapists can legitimately use adventure therapy strategies within their overall occupational therapy. Their strengths in using activity therapeutically, including in debriefing, has the potential to enhance the overall experience particularly for clients who are not comfortable in talk-based therapy. Occupational therapists have a practical approach to problem solving and skill development and can utilize adventure therapy experiences to help clients learn and practice useful skills for everyday life. Their capacity to use activity as therapy complements the work of adventure therapy practitioners from other disciplines who primarily rely on talk as therapy to facilitate therapeutic benefits. In addition, a pragmatic understanding of clients' home environment enables occupational therapists to facilitate transfer of learning to the client's everyday life effectively through using adventure therapy strategies as a means to an occupational end.

Helen Jeffrey (100000-0003-3985-409X) is a Senior Lecturer in the School of Occupational Therapy, Otago Polytechnic. Prior to this role she has worked as an occupational therapist in a variety of clinical areas, primarily mental health settings and has worked as an outdoor instructor. Helen is interested in the use of theory to inform practice, and in the use of adventure and nature-based activities within mental health settings. She is a member of the Adventure Therapy Aotearoa leadership team and the International Adventure Therapy Committee. Current research interests are evidence-based practice and adventure therapy practices in New Zealand.

Correspondence to: Helen Jeffrey, School of Occupational Therapy, Otago Polytechnic | Te Kura Matatini ki Otago, Forth Street, Private Bag 1910, Dunedin 9054, New Zealand. Email: Helen.jeffery@op.ac.nz 


\section{REFERENCES}

Alvarez, A. G., \& Stauffer, G. A. (200I). Musings on adventure therapy. The Journal of Experiential Education, 24(2), 85-85.

Ames, M. (2014). The beauties of identities. In M. A. Gass, H. L. Gillis, \& K. C. Russell (Eds). Adventure therapy: Theory, research and practice (pp. 1-17). New York: Routledge.

Bannink, F. P. (2013). Are you ready for positive cognitive behavioral therapy? The Journal of Happiness and Well-Being, I(2), 6I-69.

Berman, D. S., \& Davis-Berman, J. (2005). Positive psychology and outdoor education. The Journal of Experiential Education, 28(I), $17-24$.

Boniface, G., \& Seymour, A. (20I2). Using occupational therapy theory in practice. Chichester, UK: Wiley-Blackwell.

Creek, J. (20I4). The knowledge base of occupational therapy. In K. Bannigan, W. Bryant, J. Fieldhouse, \& J. Creek (Eds.), Creek's occupational therapy and mental health (pp. 27-48). London: Churchill Livingston.

Crisp, S. (1996). International models of best practice in wilderness and adventure therapy. Retrieved from https://files.eric.ed.gov/ fulltext/ED424052.pdf

Field, P.-A., \& Morse, J. M. (1996). Nursing research: The application of qualitative approaches. London: Croom Helm.

Gass, M. A., Gillis, H. L., \& Russell, K. C. (Eds). (2012). Adventure therapy: Theory, research and practice. New York: Routledge.

Gray, J. M. (1998). Putting occupation into practice: Occupation as ends, occupation as means. The American Journal of Occupational Therapy, 52(5), 354.

Hawkes, D., Marsh, T. I., \& Wilgosh, R. (1998). Solution focused therapy: A handbook for health care professionals. Oxford: ButterworthHeinemann.

Itin, C. M. (1998). Many paths to becoming an adventure therapist. Insight, 6(I), 4-5.

Jeffery, H. (2017). Ordinary meaning from extra-ordinary experience: Occupational therapists' use of experiential learning in adventure therapy. Retrieved from: https://www.sit.ac.nz/SITJAR\#3100219-2017

Kielhofner, G. (2009). Conceptual foundations of occupational therapy practice (4th ed.). Philadelphia: F.A. Davis Co.

Kimball, R. O., \& Bacon, S. B. (1993). Wilderness challenge model. In M. A. Gass (Ed.). Adventure therapy: Therapeutic applications of adventure programming. lowa, USA: Kendall Hunt Publishing Company.

Langer, E. J. (1989). Mindfulness. Reading, MA: Addison Wesley Longman.

Miller, W. R. (2013). Motivational interviewing: Helping people change (3rd ed.). London: Guilford Press.

Mossman, S. E. (2005). What works with youth? An evaluation of the Adventure Development Counselling programme. Christchurch, NZ: University of Canterbury.

Neergaard, M. A., Olesen, F., Andersen, R. S. \& Sondergaard, J. (2009). Qualitative description - the poor cousin of health research? British Medical Council - Medical research methodology, 9(52). Retrieved from http://www.biomedcentral.com/l47/-2288/9/52

Newes, S. L., \& Bandoroff, S. (2004). What is adventure therapy? In S. Newes \& S. Bandoroff (Eds). Coming of age: The evolving field of adventure therapy (pp. 1-30). Boulder, Colorado: Association for Experiential Education.

Sandelowski, S. (2000). Whatever happened to qualitative description? Research in Nursing and Health, 23, 334-340.

The World Federation of Occupational Therapists (2018). Definitions of occupational therapy from member organisations. Retrieved from https://www.wfot.org/resources/definitions-of-occupational-therapy-from-member-organisations

Trombly, C. A. (1995). Occupation: Purposefulness and meaningfulness as therapeutic mechanisms: 1995 Eleanor Clarke Slagle Lecture. American Journal of Occupational Therapy, 49(10), 960-972.

Wasserburger, K. (2012). Foundations of adventure therapy. In M. A. Gass, L. Gillis, \& K. C. Russell (Eds). Adventure therapy: Theory, research and practice (pp. 69-93). New York: Routledge. 